Pathologe 2014 · [Suppl 2] · 35:307-307

DOI 10.1007/s00292-014-1972-5

Online publiziert: 15. November 2014

c) Springer-Verlag Berlin Heidelberg 2014
H.E. Gabbert

Institut für Pathologie, Universitätsklinikum Düsseldorf

\section{Waldemar Hort}

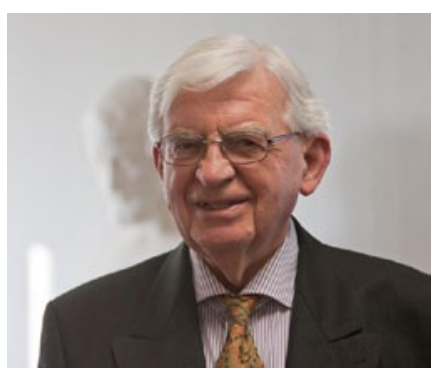

Waldemar Hort (mit freundl. Genehmigung der Heinrich-Heine-Universität Düsseldorf)

Am 05.06.2014 verstarb in Düsseldorf Prof. (Emeritus) Dr. med. Waldemar Hort im Alter von 89 Jahren.

Waldemar Hort war am 08.05.1925 als Sohn eines Finanzbeamten in Berlin zur Welt gekommen und damit, wie er selbst gerne betont hat, ein „echter Berliner“. Er besuchte das humanistische Gymnasium in Berlin und wurde unmittelbar nach dem Abitur zunächst zum Arbeitsdienst nach Ostpreußen und anschließend als Sanitätssoldat eingezogen. An seinem 20. Geburtstag - dem Tag des Kriegsendes geriet er noch in russische Kriegsgefangenschaft, konnte aber sehr rasch fliehen und sich über die Tschechoslowakei nach Berlin durchschlagen. Angesichts der prekären Versorgungslage der Stadt Berlin versuchte er zunächst, durch eine Hilfsarbeit in einer Gärtnerei seine Familie mit Lebensmitteln zu unterstützen. Schon bald konnte er jedoch an der HumboldtUniversität sein Medizinstudium (19461951) aufnehmen und traf dort auf Robert Rössle, bei dem er promovierte und der nicht nur sein Interesse am Fach Pathologie weckte, sondern auch seinen weiteren Lebensweg prägen sollte.

Nach einer Tätigkeit im Urban-Krankenhaus in Berlin ging er 1952 als Assis- tenzarzt an das Pathologische Institut der Philipps-Universität Marburg, wo er seine spätere Frau Hedwig kennenlernte, die ebenfalls Assistenzärztin am Pathologischen Institut war und die eine Tochter und zwei Söhne zur Welt brachte.

Im Jahr 1960 habilitierte sich Waldemar Hort in Marburg und folgte danach seinem Chef Johannes Linzbach nach Göttingen. Mit seinem Ruf 1969 auf den Lehrstuhl für Pathologie in Marburg erfüllte sich nicht nur ein beruflicher Traum, sondern auch der Traum von der Rückkehr in die von ihm so geliebte Universitätsstadt. Dennoch folgte er 1977 einem Ruf auf den Lehrstuhl des Instituts für „Allgemeine Pathologie und Pathologische Anatomie“ der Universität Düsseldorf, wo er bis zu seiner Emeritierung im Jahr 1990 tätig war.

Seine Forschungsschwerpunkte waren die Gefäß- und Herzpathologie. In Würdigung seiner wissenschaftlichen Verdienste wurde er 1984 zum Präsidenten der Deutschen Gesellschaft für Kardiologie gewählt und war darüber hinaus 19861990 Sprecher des Sonderforschungsbereichs „Koronare Herzerkrankungen“ an der Medizinischen Fakultät der HeinrichHeine-Universität Düsseldorf.

Nachhaltig in Erinnerung bleibt Waldemar Hort auch als Herausgeber und Mitautor des Handbuchs „Pathologische Anatomie des Herzens und seiner Hüllen“, im Rahmen der Handbuchreihe „Spezielle Pathologie“, herausgegeben von Doerr, Seifert und Uehlinger. Nicht unerwähnt bleiben soll seine Ehrenmitgliedschaft in der Deutschen Gesellschaft für Kardiologie-, Herz- und Kreislaufforschung.

Auch nach seiner Emeritierung war Waldemar Hort regelmäßig Gast in unserem Institut und blieb damit allen Mit- arbeitern eng verbunden. Durch die von ihm ins Leben gerufene „Hedwig und Waldemar Hort" Stipendienstiftung wird er immer auch den Studenten und der Heinrich-Heine-Universität Düsseldorf in Erinnerung bleiben.

Das Institut für Pathologie und seine Mitarbeiter wie auch die Medizinische Fakultät der Heinrich-Heine-Universität Düsseldorf und die Deutsche Pathologie trauern um einen hochangesehenen und über seine fachliche Tätigkeit hinaus engagierten Wissenschaftler und Menschen.

Helmut Gabbert, Düsseldorf

\section{Korrespondenzadresse}

Prof. Dr. H.E. Gabbert

Institut für Pathologie,

Universitätsklinikum Düsseldorf

Moorenstr. 5, 40225 Düsseldorf

gabbert@med.uni-duesseldorf.de 